\title{
Separation and Purification of Ursolic Acid from Cynomorium songaricum Exacts with Macroporous Resins
}

\author{
Xifeng Zhang1,2, Wangxu Hou' ${ }^{1}$ Xue Zheng1,2* \\ ${ }^{1}$ The College of Agriculture and Biotechnology (CAB), Hexi University, Zhangye, China \\ ${ }^{2}$ Key Laboratory of Hexi Corridor Resources Utilization of Gansu, Zhangye, China \\ Email: *curiouslysxsd@163.com
}

How to cite this paper: Zhang, X.F., Hou, W.X. and Zheng, X. (2018) Separation and Purification of Ursolic Acid from Cynomorium songaricum Exacts with Macroporous Resins. Open Access Library Journal, 5: e4475.

https://doi.org/10.4236/oalib.1104475

Received: March 6, 2018

Accepted: May 21, 2018

Published: May 24, 2018

Copyright $\odot 2018$ by authors and Open Access Library Inc.

This work is licensed under the Creative Commons Attribution International License (CC BY 4.0).

http://creativecommons.org/licenses/by/4.0/

\begin{abstract}
Enrichment and purification of ursolic acid from Cynomorium songaricum exacts were studied using five macroporous resins. The static tests indicated that D101 resin was appropriate and its adsorption data were well fitted to the Langmuir and Freundlich isotherms. To optimize the separation process, dynamic adsorption and desorption tests were carried out. The optimal adsorption parameters were initial concentrations in sample solution of $3.8 \mathrm{mg} / \mathrm{mL}$, $\mathrm{pH}$ of 6.0 , sample loading amount of $5 \mathrm{BV}$, flow rate of $2 \mathrm{BV} / \mathrm{h}$, and temperature of $25^{\circ} \mathrm{C}$. The optimal desorption parameters were $70 \%$ ethanol $5 \mathrm{BV}$, then $80 \%$ ethanol $10 \mathrm{BV}$, and flow rate of $2 \mathrm{BV} / \mathrm{h}$. After one run treatment with AB-8 resin, the content of total flavonoids in the product increased from $9.83 \%$ to $67.8 \%$, and the recovery yield was $84.02 \%$. The results showed that AB-8 resin revealed a good ability to enrichment total flavonoids from $\mathrm{Cy}$ nomorium songaricum, and the method can be referenced for the enrichment of total flavonoids from other materials.
\end{abstract}

\section{Subject Areas \\ Biotechnology}

\section{Keywords}

Ursolic Acid, Macroporous Resins, Cynomorium songaricum Rupr.

\section{Introduction}

Cynomorium songaricum Rupr., also known as "Suoyang" in China, has been widely used in traditional Chinese medicine, which is an obligate root parasitic plant. Its most common host is Nitraria tangutorum Bobr. [1], which plays an important ecological role as a windbreak and in sand fixation. It is mainly dis- 
tributed in Northwestern China and Central Asia and is used as healthy foods and nutrients by local people [2]. Nowadays, the stems of $C$. songaricum are widely used as functional food ingredients or supplements. For example, the wine containing extract of $C$. songaricum as an ingredient is popular in China. Pharmacological research had demonstrated that anti-oxidation was one of the main activities of $C$. songaricum [3]. C. songaricum also has other activities, including anti-HIV [4], anti-aging [5], improving sexual function, and immunity [6].

Among the effective ingredients of $C$. songaricum, ursolic acid and polysaccharides are the most abundant effective components in C. songaricum [7]. In view of these well-known pharmacological properties, $C$. songaricum flavonoids have great potential to be used as a clinical therapeutic agent. Hence, more scientific researches are needed to confirm these bioactivities. Therefore, it is essential to apply low-cost and effective technology for the extraction and further purification of $C$. songaricum ursolic acid with good recovery and high content of flavonoids.

There are some methods for finding the concentration of active constituents from traditional Chinese herbs, such as solid-liquid extraction [8] [9] or solvent extraction [10] [11], column chromatography [12] [13] and the preparative high-speed counter-current chromatography [14] [15] [16]. However, these separation methods have limitations such as low extraction yield, the inclusion of many various steps, intense energy consumption, low efficiency and labor intensiveness. Comparatively, separation methods by macroporous resins are popular as a simple procedure, easy operation, low cost, high efficiency and easy generation [17] [18]. Therefore, there has been a growing interest in employing macroporous resins to separate bioactive components from crude extracts of herbal raw materials. For example, macroporous resins have been successfully used in the enrichment of polysaccharide from Astragalus extracts [19], pedunculoside and syringin from Ilex rotunda Thunb extracts [20], steviol glycosides from Stevia rebaudiana bertoni [21]. However, there is no report on using macroporous resins to enrich and separate ursolic acid from $C$. songaricum extracts so far.

In the present study, five resins with different polarities were used to investigate the adsorption and desorption properties of ursolic acid, and to develop a simple and efficient process for preliminary enrichment and separation of ursolic acid from $C$. songaricum extracts with the optimal resin. The parameters influencing the adsorption and desorption properties of ursolic acid were optimized and the experimental equilibrium data at different temperatures were fitted to Langmuir and Freundlich isotherms. The results from this study would be significant in order to develop a preparative method for the separation of ursolic acid from C. songaricum extracts.

\section{Materials and Methods}

\subsection{Materials and Instruments}

C. songaricum was obtained from microalgae engineering research center of 
Gansu Province, China. The sample was dried at room temperature, powdered by an electric grinder and passed through a 40 mesh sieve. The rutin standard was purchased from the National Institute for the Control of Pharmaceutical Drugs in Beijing, China. All other chemicals used were of analytical-reagent grade.

Macroporous resins including NKA-9, NKA, D101, AB-8 and HPD-750 were purchased from the Chemical Plant of NanKai University (Tianjin, China). Their physical and chemical properties are listed in Table 1 . They were pretreated with $\mathrm{HCl}$ and $\mathrm{NaOH}$ solutions to remove the monomers and porogenicagents trapped inside the pores during the synthesis process. Prior to use, the resins were soaked in ethanol for $24 \mathrm{~h}$, and subsequently was repeatedly washed with the ethanol until there was no residue after distillation, and finally washed with sufficient distilled water.

SP-721 spectrophotometer (Spectrum Instruments Corporation, Shanghai, China) was used for analysis of total flavonoids, RE-2000A rotary evaporator (Gongyi Jinghua Instrument Factory, Henan, China) was used for concentration of samples.

\subsection{Preparation of Crude Ursolic Acid Extract}

The dried powder was extracted twice with $1000 \mathrm{~mL} 100 \%$ ethanol at $65^{\circ} \mathrm{C}$ for 3 $\mathrm{h}$. The extract was centrifuged and the supernatant filtered through a $0.45 \mathrm{um}$ filter membrane, concentrated to remove the ethanol. The content of ursolic acid in extracts was $7.48 \%$. The crude extract could be diluted by deionized water to obtain a different concentration used for the following experiments.

\subsection{Determination of Ursolic Acid Content}

The content of total flavonoids was determined by the colorimetric method with some modifications [22] [23]. The separations of ursolic acid were carried out using the ACE 5C18 $250 \times 4.6 \mathrm{~mm}$ (Advanced Chromatography Technologies, Aberdeen, Scotland) column. The mobile phase was composed of methanol and water $(90 / 10, \mathrm{v} / \mathrm{v})$. The flow rate was $0.6 \mathrm{~mL} / \mathrm{min}$ and injection volume was 10 $\mu \mathrm{L}$. Absorption was measured at $203 \mathrm{~nm}$. Quantification was carried out by the external standard method and calibration curves were obtained.

\subsection{Static Adsorption and Desorption Tests}

\subsubsection{Adsorption and Desorption Capacities, Desorption Ratio}

The static adsorption and desorption tests were carried out in a water bath mode. $1 \mathrm{~g}$ resin was introduced into a $100 \mathrm{~mL}$ triangular flask. $30 \mathrm{~mL}$ of crude exact of ursolic acid $(4 \mathrm{mg} / \mathrm{mL})$ was added to each flask. The flasks were kept in the shaking water bath at $150 \mathrm{r} / \mathrm{min}$ and $25^{\circ} \mathrm{C}$ until adsorption reaching equilibrium. After removed of the residual extract solutions, the adsorb ate-laden resins were washed with $15 \mathrm{~mL}$ deionized water for 3 times and desorbed with 50 $\mathrm{mL} 80 \%$ ethanol-water solution. During the desorption process, the flasks were shaken at $150 \mathrm{r} / \mathrm{min}, 25^{\circ} \mathrm{C}$ for $12 \mathrm{~h}$. 
Table 1. Physical properties of the used macroporos resins.

\begin{tabular}{ccccc}
\hline Name & $\begin{array}{c}\text { Particle diameter } \\
(\mathbf{m m})\end{array}$ & $\begin{array}{c}\text { Surface area } \\
\left(\mathrm{m}^{2} / \mathrm{g}\right)\end{array}$ & $\begin{array}{c}\text { Average pore diameter } \\
(\mathrm{nm})\end{array}$ & Polarity \\
\hline NKA-9 & $0.3-1.25$ & $250-290$ & $15.5-16.5$ & Polar \\
NKA & $0.3-1.25$ & $160-200$ & $14.5-15.5$ & Polar \\
D101 & $0.3-1.25$ & $\geq 400$ & $9.0-11.0$ & Non-polar \\
AB-8 & $0.3-1.25$ & $480-520$ & $13.0-14.0$ & Weak-polar \\
HPD-750 & $0.3-1.25$ & $650-700$ & $8.5-9.0$ & Mild-polar \\
\hline
\end{tabular}

The selectivity of resins was based on the capacities of adsorption $\left(Q_{e}\right)$, capacities of desorption $\left(Q_{d}\right)$, and ratio of desorption $(D)$, which were quantified according to the following equations:

$$
\begin{gathered}
Q_{e}=\left(C_{0}-C\right)_{e} \times \frac{V i}{W} \\
Q_{d}=\frac{C_{d} \times V_{d}}{W} \\
D=\frac{C_{d} \times V_{d}}{\left(C_{0}-C_{e}\right) V_{i}} \times 100 \%
\end{gathered}
$$

where $Q_{e}$ was the adsorption capacity at adsorption equilibrium(mg/g dry resin). $Q_{d}$ was the desorption capacity after adsorption equilibrium ( $\mathrm{mg} / \mathrm{g}$ dry resin). $C_{0}, C_{e}$ and $C_{d}$ were the initial, absorption equilibrium and desorption concentrations of analyte in the solutions, respectively $(\mathrm{mg} / \mathrm{mL}) . V_{i}$ and $V_{d}$ were the volume of the initial sample and desorption solution $(\mathrm{mL})$, respectively. $W$ was the dry weight of resin (g), and $D$ was the desorption ratio (\%).

The impact of $\mathrm{pH}$ on the adsorption capacities of ursolic acid was carried out by mixing $1 \mathrm{~g}$ (dry weight) of hydrated selected resin with sample solutions (30 $\mathrm{mL}$ each) in the $\mathrm{pH}$ range of $4.0-8.0$. The sample $\mathrm{pH}$ was adjusted to the desired value with hydrochloric acid or ammonia solution. Then, the flasks were shaken at $25^{\circ} \mathrm{C}$ for $6 \mathrm{~h}$.

\subsubsection{Adsorption Kinetics}

The adsorption kinetics curve of total flavonoids on the preliminarily selected resins was studied according to the aforementioned method. The concentrations of ursolic acid in liquid phase were monitored at equal time intervals till equilibration at $25^{\circ} \mathrm{C}$.

\subsubsection{Adsorption Isotherms}

In order to investigate the effect of initial concentration and temperature on the ursolic acid absorption, experiments of adsorption isotherm on selected resin were performed. Five aliquots of $30 \mathrm{~mL}$ sample solutions at different concentrations were contacted with pre-weighed amounts of hydrated resins (equal to $1 \mathrm{~g}$ dry resin) in a constant temperature shaker at $25^{\circ} \mathrm{C}, 30^{\circ} \mathrm{C}$ and $35^{\circ} \mathrm{C}$ for $6 \mathrm{~h}$.

The Langmuir and Freundlich models were used to evaluate the adsorption 
behavior between adsorbate and adsorbent [24] [25] [26].

Langmuir isotherms:

$$
Q_{e}=\frac{Q_{m} \times K_{L} \times C_{e}}{1+K_{L} \times C_{e}}
$$

Freundlich isotherms:

$$
Q_{e}=K_{F} \times C_{e}^{1 / n}
$$

where $Q_{e}$ and $C_{e}$ were the same as those in Equation (1), $K_{L}(\mathrm{mg} / \mathrm{mL})$ and $Q_{m}$ (mg/g resin) were the Langmuir constants. $K_{L}$ was the dissociation constant of the adsorption interaction and $Q_{m}$ was the maximum adsorption capacity. $K_{F}$ $(\mathrm{mg} / \mathrm{mL})$ and $n$ were the Freundlich constants.

\subsubsection{Dynamic Adsorption and Desorption Tests}

Dynamic adsorption and desorption experiments were carried out in a glass column $(17 \times 120 \mathrm{~mm})$ wet-packed with the selected resin and the BV of the resin was $10 \mathrm{~mL}$. The flow rate of sample solution was $2 \mathrm{BV} / \mathrm{h}$ through the glass column and the ursolic acid content in the effluent liquid was monitored by the colorimetric method till equilibrium adsorption. After adsorption equilibrium, the column was firstly washed with deionized water, and then eluted with different concentrations ethanol at the flow rate of $2.0 \mathrm{BV} / \mathrm{h}$. Dynamic adsorption and desorption tests were repeated three times under optimal conditions, and the recovery of ursolic acid were calculated.

\section{Result and Discussion}

\subsection{Adsorption and Desorption Capacities, Desorption Ratio}

According to the "like dissolve like" rule, given ursolic acid contain non-polar phenyl group and polar multi-hydroxyl groups, either non-polar resins or polar resins were applicable to adsorption of ursolic acid. So, five macroporous resins ranging from non-polarity to polarity were employed for enrichment the ursolic acid.

As shown in Table 2, D101, AB-8 and HPD-750 exhibited adsorption capacities $(97.2 \mathrm{mg} / \mathrm{g}$ resin, $90.6 \mathrm{mg} / \mathrm{g}$ resin and $80.26 \mathrm{mg} / \mathrm{g}$ resin, respectively) for ursolic acid. The result indicates that the three resins had good adsorption selectivity in contrast with other resins. However, for the desorption ratios of ursolic

Table 2. Adsorption capacities, adsorption and desorption ratios of total flavonoids on different macroporous resins.

\begin{tabular}{cccc}
\hline Name & $Q_{e}(\mathrm{mg} / \mathrm{g}$ resin $)$ & $Q_{d}(\mathrm{mg} / \mathrm{g}$ resin $)$ & $D(\%)$ \\
\hline NKA-9 & $45.02 \pm 0.45$ & $12.75 \pm 0.24$ & $28.32 \pm 0.42$ \\
NKA & $51.2 \pm 0.35$ & $17.22 \pm 0.74$ & $33.63 \pm 0.17$ \\
D101 & $97.2 \pm 0.47$ & $85.23 \pm 0.27$ & $87.68 \pm 0.14$ \\
AB-8 & $90.6 \pm 0.19$ & $76.10 \pm 0.27$ & $83.99 \pm 0.27$ \\
HPD-750 & $80.26 \pm 0.15$ & $45.23 \pm 0.22$ & $56.31 \pm 0.29$ \\
\hline
\end{tabular}


acid, they were $87.68 \%$ (D101), 83.99\% (AB-8) and 56.31\% (HPD-750), respectively, which illustrated that it was disadvantageous to the desorption of ursolic acid for D101 and AB-8.

Compared with other resins, D101 resin had a much higher adsorption capacity as well as the higher desorption ratio. Therefore, on full consideration of the adsorption/desorption properties and desorption ratio, D101 was selected as a suitable resin for separating ursolic acid in further study.

\subsection{Effect of Sample Solution pH Value}

The $\mathrm{pH}$ of the sample solution significantly affected the adsorption capacity of ursolic acid on D101 resin. As shown in Figure 1(a), the adsorption capacity initially increased to reach its peak value at $\mathrm{pH} 6$, and then decreased gradually. The result indicates that hydrogen bonding may play an important role in the adsorption process on $\mathrm{D} 101$ resin. At a higher $\mathrm{pH}$ value, the hydrogen bonding interactions were reduced, because the phenolic hydroxyl groups in ursolic acid dissociated to $\mathrm{H}^{+}$and their corresponding anions, thus resulting in the lower adsorption capacity. Hence, suitable $\mathrm{pH}$ value for the following tests was adjusted to 6 .

\subsection{Adsorption Kinetics on D101 Resin}

It is not enough for assessing the performance of a resin to use only static adsorption/desorption ratio tests. A suitable resin must also have high adsorption rates. The adsorption kinetics curves for the ursolic acid on D101 resin were obtained at $25^{\circ} \mathrm{C}$. As shown in Figure $1(\mathrm{~b})$, in the beginning, the adsorption capacity of D101 increased rapidly within $4 \mathrm{~h}$, and then increased slowly, finally, reaching equilibrium at around $5 \mathrm{~h}$. The fast initial step is likely due to the occurrence of adsorption in the easily accessible mesopores of the particles, proceeding with low mass transfer in the bulk solution. The later slower uptake, on the other hand, is indicative of processes with high intraparticle mass transfer resistance [27].

\subsection{Adsorption Isotherms on D101 Resin}

To further explore the adsorption properties of the ursolic acid on D101, equilibrium adsorption isotherms on D101 resin were investigated with various initial concentrations of ursolic acid at $25^{\circ} \mathrm{C}, 30^{\circ} \mathrm{C}$ and $35^{\circ} \mathrm{C}$. The initial concentrations of the ursolic acid in the solutions were 2.0, 2.7, 3.3, 3.8 and $4.0 \mathrm{mg} / \mathrm{mL}$, respectively. As shown in Figure 1(c), the adsorption capacity increased with the initial concentration and reached the saturation plateau when the initial concentration of the ursolic acid was $3.8 \mathrm{mg} / \mathrm{mL}$. Thus $3.8 \mathrm{mg} / \mathrm{mL}$ ursolic acid was used as initial concentration of sample solution in the following tests.

In addition, for the interpretation of the equilibrated relationship between the solutes and the adsorbents, the Langmuir and Freundlich isotherms were used in this study. The Langmuir equation is the best known and the frequently used 


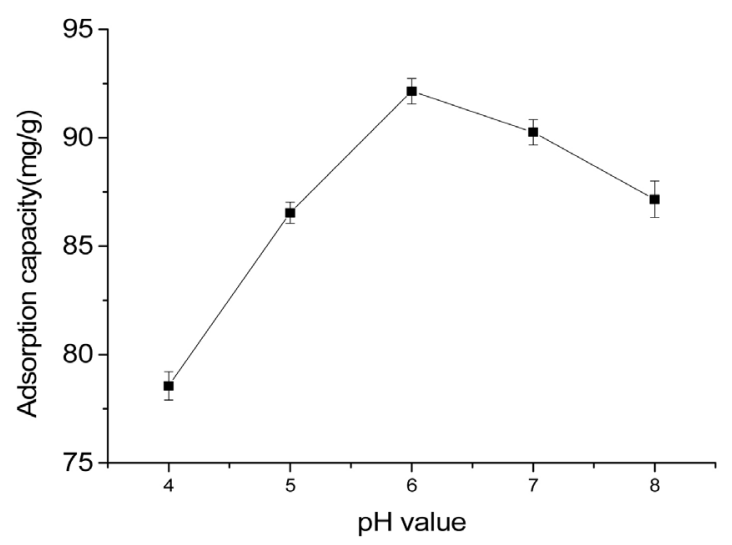

(a)

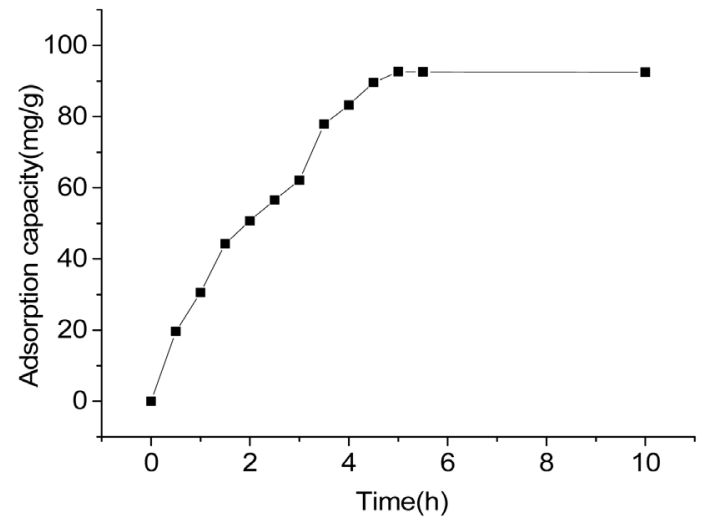

(b)

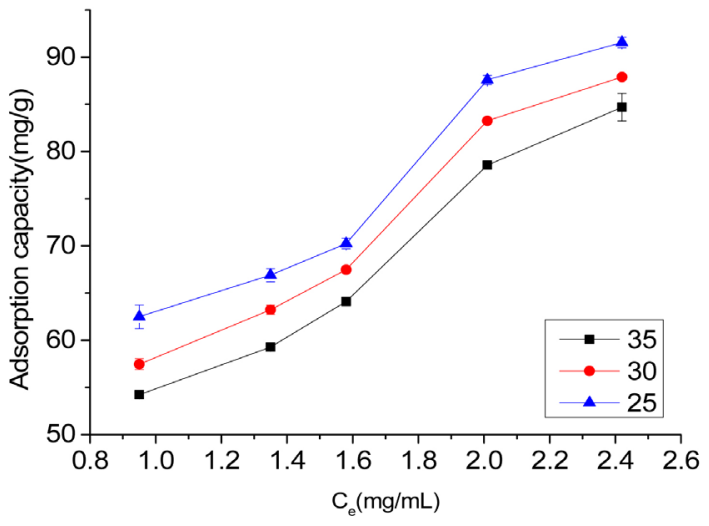

(c)

Figure 1. Effect of $\mathrm{pH}$ value on the adsorption capacity of ursolic acid on D101 resin (a); adsorption kinetics curve for theursolic acid on D101 resin at $25^{\circ} \mathrm{C}(\mathrm{b})$; and adsorption isotherms for the ursolic acid on D101 resin at different temperatures (c) $\left(25^{\circ} \mathrm{C}, 30^{\circ} \mathrm{C}\right.$ and $\left.35^{\circ} \mathrm{C}\right)$.

equation to describe the adsorption behaviour of monomolecular layer [28], whereas the Freundlich equation is widely used to describe the adsorption behaviour of monomolecular layer as well as that of the multi-molecular layer [29]. Table 3 listed the two isotherm equations at different temperatures and two important parameters: $Q_{m}$ value (obtained from the Langmuir isotherm) and $1 / \mathrm{n}$ 
Table 3. Langmuir and Freundlich parameters of ursolic acid on D101 resin at different temperature.

\begin{tabular}{ccccc}
\hline Temperature $\left({ }^{\circ} \mathrm{C}\right)$ & Langmuir equation & $\mathbf{R}^{2}$ & Freundlich equation & $\mathbf{R}^{2}$ \\
\hline 25 & $C_{e} / Q_{e}=0.0096 C_{e}+0.0084$ & 0.9962 & $Q_{e}=73.06 C_{e} 0.3801$ & 0.9817 \\
30 & $C_{e} / Q_{e}=0.0074 C_{e}+0.0079$ & 0.9934 & $Q_{e}=64.08 C_{e} 0.4364$ & 0.9807 \\
35 & $C_{e} / Q_{e}=0.0074 C_{e}+0.0088$ & 0.9923 & $Q_{e}=56.39 C_{e} 0.4299$ & 0.9801 \\
\hline
\end{tabular}

value (obtained from the Freundlich isotherm). The correlations (0.9923 - 0.9962) for ursolic acid on D101 indicated that the two models were suitable for describing the tested adsorption system in the concentration ranges studied.

Generally, in the Freundlich equation, the adsorption was easy to carry out when $1 / \mathrm{n}$ value was between 0.1 and 0.5 , and it was difficult to take place if $1 / \mathrm{n}$ value was above 1 [30]. It can be seen from Table 3 , the $1 / \mathrm{n}$ values were all between 0.3 and 0.5 , indicated that the adsorption of the ursolic acid on D101 resin took place easily.

Within the ranges of temperatures investigated, the adsorption capacities decreased with the temperature increase (Figure 1(c)), which indicated the adsorption process was a thermopositive process. Similar results were obtained for the enrichment other compounds using macroporous resin [31]. Therefore, $25^{\circ} \mathrm{C}$ was selected in the following experiments.

\subsection{Dynamic Breakthrough Curve on D101 Resin}

The dynamic leakage curve on D101 resin at the flow rate of $2 \mathrm{BV} / \mathrm{h}$ was obtained based on the volume of effluent liquid and the concentration of solute here in (Figure 2). In general, when the adsorption reaches the break point, the adsorption affinity decreases, even disappears, and the solutes leak from the resin. Hence, it is important to set up the leakage curve in order to calculate the quantity of resin, and the feed volume of sample solution. The adsorption capability is usually thought to reach the saturation when the concentration in effluent is $10 \%$ of the original concentration [32]. As shown in Figure 2, no obvious leakage of the ursolic acid in the effluent liquid was observed before $6 \mathrm{BV}$. Then, the concentration of the ursolic acid in the effluent liquid increased rapidly until it reached a steady plateau in $8 \mathrm{BV}$. The breakthrough point was captured when the feed volume of sample solution was approximate $5 \mathrm{BV}(50 \mathrm{~mL})$.

\subsection{Dynamic Desorption Tests on D101 Resin}

Dynamic desorption was performed with gradient eluent at the flow rate of 2 $\mathrm{BV} / \mathrm{h}$. Different elution solvents with the same volume of $5 \mathrm{BV}$ were used to desorb the ursolic acid when the sample loading amount was $5 \mathrm{BV}$. At the $35 \%$ ethanol, the ursolic acid was hardly desorbed. When the ethanol concentration was over $35 \%$, the desorption ability increased sharply and reached a peak value at $80 \%$ ethanol. Hence, a gradient elution procedure with $35 \%$ and $80 \%$ ethanol at a flow rate of $2 \mathrm{BV} / \mathrm{h}$ was applied for desorption of the ursolic acids. In 


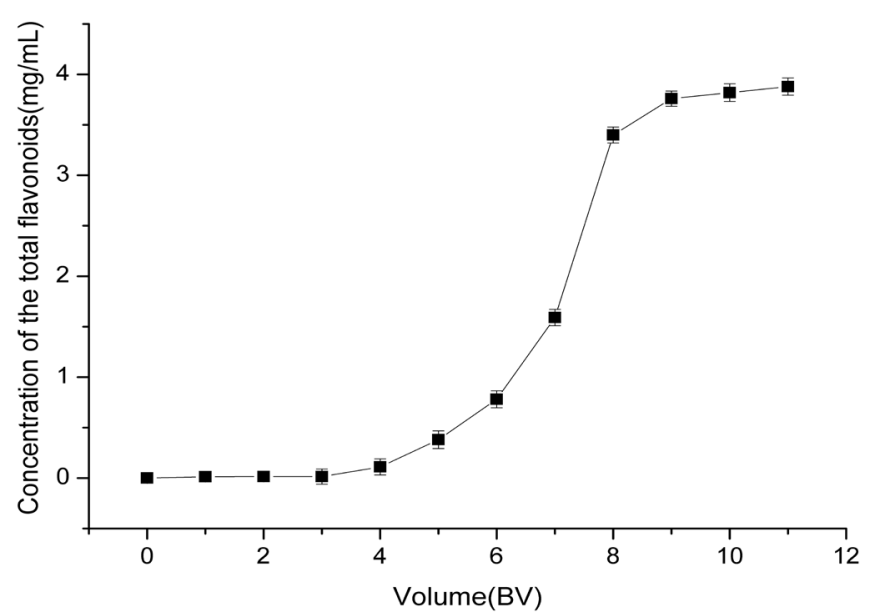

Figure 2. Dynamic breakthrough curves of ursolic acid on AB-8 resin.

Table 4. Results of gradient elution of the ursolic acids on column packed with D101 re$\sin$.

\begin{tabular}{ccccc}
\hline $\begin{array}{c}\text { Concentration of } \\
\text { ethanol (\%) }\end{array}$ & $\begin{array}{c}\text { Mass of dried } \\
\text { residue (mg) }\end{array}$ & $\begin{array}{c}\text { Mass of the ursolic } \\
\text { acids (mg) }\end{array}$ & $\begin{array}{c}\text { Content of the } \\
\text { ursolic acids (\%) }\end{array}$ & $\begin{array}{c}\text { Recovery of the } \\
\text { ursolic acids (\%) }\end{array}$ \\
\hline 0 & $17.2 \pm 0.25$ & 0 & 0 \\
35 & $29.0 \pm 0.31$ & 0 & 0 \\
70 & $64.4 \pm 0.19$ & $28.6 \pm 0.98$ & $62.9 \pm 0.91$ & \\
80 & $116.2 \pm 0.35$ & $95.3 \pm 0.85$ & $74.9 \pm 1.51$ & \\
Collection of $60-70$ & $180.6 \pm 0.85$ & $113.9 \pm 0.75$ & $63.06 \pm 0.86$ & $76.02 \pm 1.22$ \\
\hline
\end{tabular}

addition, the elution volume of each ethanol concentration was modified under the guidance of absorbance.

The dried extract of $C$. songaricum (1.5 g) was dissolved in deionized water. The ursolic acids were enriched and purified from the sample solution with D101 resin. According to content analysis of ursolic acids, the elution scheme was modified as $5 \mathrm{BV}$ deionized water, $5 \mathrm{BV} 30 \%$ ethanol, $5 \mathrm{BV}$ of $70 \%$ ethanol and $10 \mathrm{BV}$ of $80 \%$ ethanol. As shown in Table 4, non-adsorption components were firstly washed out by $5 \mathrm{BV}$ deionized water. Subsequently, some impurities were removed by elution of 5 BV 35\% ethanol. The following 10 BV of $80 \%$ ethanol elution gave the product rich in the ursolic acids. After separation on D101 resin by the gradient elution, the content of the ursolic acids reached $63.06 \%$, which was 10.1 -fold to those in extract of C. songaricum, and the recovery yields were $76.02 \%$.

\section{Conclusions}

The present study reported experimental data on the enrichment and separation of the ursolic acids from extracts of $C$. songaricum at various operating parameters, using five macroporous resins differing in chemical and physical properties. Among the resins used, the most effective resin (D101) was successfully applied 
to obtain a product of the ursolic acids with higher content. The optimal enrichment and purification conditions for ursolic acid were confirmed as follows: for adsorption: concentration of ursolic acid in sample solution 3.8 $\mathrm{mg} / \mathrm{mL}$; $\mathrm{pH} 5$; feed volume $5 \mathrm{BV}$; flow rate $2 \mathrm{BV} / \mathrm{h}$; temperature $25^{\circ} \mathrm{C}$; for desorption: $70 \%$ ethanol $5 \mathrm{BV}$, then $80 \%$ ethanol $10 \mathrm{BV}$; flow rate $2 \mathrm{BV} / \mathrm{h}$. The content of ursolic acids in the product was increased 10.1 -fold from $7.84 \%$ to $63.06 \%$, with a recovery yield of $76.02 \%$.

In conclusion, this adsorption-desorption method using D101 resin is suitable for the separation of the ursolic acids from extracts of $C$. songaricum extract due to its simplicity of the method, high efficiency and likely ease in scaling-up.

\section{References}

[1] Liu, G.D., Chen, G.L., Li, W. and Li, C.X. (2013) Genetic and Phytochemical Diversities of Cynomorium songaricum Rupr. in Northwest China Indicated by ISSR Markers and HPLC-Fingerprinting. Biochemical Systematics and Ecology, 48, 34-41. https://doi.org/10.1016/j.bse.2012.12.004

[2] Ma, L.J., Chen, G.L., Jin, S.W. and Wang, C.X. (2006) The Anti-Aging Effect and the Chemical Consttuents of Cynomorium songaricum Rupr. Acta Horticulturae, $765,23-30$.

[3] Jin, S.W., Chen, G.L., Du, J.J.M., Wang, L.H., Ren, X. and An, T.Y. (2014) Antioxidant Properties and Principal Phenolic Compositions of Cynomorium songaricum Rupr. International Journal of Food Properties, 17, 13-25. https://doi.org/10.1080/10942912.2011.587623

[4] Ma, C.M., Nakamura, N., Miyashiro, H., Hattori, M. and Shimotohno, K. (1999) Inhibitory Effects of Constituents from Cynomorium songaricum and Related Triterpene Derivatives on HIV-1 Protease. Chemical and Pharmaceutical Bulletin, 47, 141-145.

[5] Ma, L.J., Chen, G.L., Nie, L.S. and Ai, M. (2009) Effect of Cynomorium songaricum Polysaccharide on Telomere Length in Blood and Brain of D-Galactose-Induced Senescence Mice. China Journal of Chinese Materia Medica, 34, 1257-1260.

[6] Zhang, X.R., Jia, Z.P., Li, M.X., Wang, J., Yin, Q., Luo, J.D. and Liu, H.Y. (2008) Study on the Effect of Part III from Cynomorium songaricum on Immunosuppressive Mice Induced by Cyclophosphamide. Journal of Chinese Medicinal Materials, 31, 407-409.

[7] Tao, J., Tu, P., Xu, W. and Chen, D. (1999) Studies on Chemical Constituents and Pharmacological Effects of the Stem of Cynomorium songaricum Rupr. Journal of Chinese Medicinal Materials, 24, 292-294.

[8] Zheng, L.L., Wang, D., Li, Y.Y., Peng, H.Y., Yuan, M.Y. and Gao, F. (2014) Ultrasound-Assisted Extraction of Total Flavonoids from Aconitum gymnandrum. Pharmacognosy Magazine, 10, 141-146. https://doi.org/10.4103/0973-1296.127364

[9] Cai, F., Xiao, C., Chen, Q., Ouyang, C., Zhang, R., Wu, J. and Liu, C. (2014) Orthogonal Test Design for Optimizing the Extraction of Total Flavonoids from Flos $\mathrm{Pu}$ eraria. African Journal of Pharmacy and Pharmacology, 8, 1-8. https://doi.org/10.5897/AJPP2013.3939

[10] Srinivas, K., King, J.W., Monrad, J.K., Howard, L.R. and Zhang, D. (2011) Pressurized Solvent Extraction of Flavonoids from Grape Pomace Utilizing Organic Acid Additives. Italian Journal of Food Science, 23, 90-105.

[11] Bi, W., Tian, M. and Row, K.H. (2013) Evaluation of Alcohol-Based Deep Eutectic 
Solvent in Extraction and Determination of Flavonoids with Response Surface Methodology Optimization. Journal of Chromatography A, 1285, 22-30. https://doi.org/10.1016/j.chroma.2013.02.041

[12] Yin, H., Zhang, S., Long, L., Yin, H., Tian, X., Luo, X. and He, S. (2013) The Separation of Flavonoids from Pongamia pinnata Using Combination Columns in High-Speed Counter-Current Chromatography with a Three-Phase Solvent System. Journal of Chromatography A, 1315, 80-85.

https://doi.org/10.1016/j.chroma.2013.09.010

[13] Dmitrienko, S.G., Stepanova, A.V., Kudrinskaya, V.A. and Apyari, V.V. (2012) Specifics of Separation of Flavonoids by Reverse Phase High Performance Liquid Chromatography on the Luna 5u C18(2) Column. Moscow University Chemistry Bulletin, 67, 254-258.

[14] Gonçalves, M.S., Vieira, I.J.C., Oliveira, R.R. and Braz-Filho, R. (2011) Application of Preparative High-Speed Counter-Current Chromatography for the Separation of Two Alkaloids from the Roots of Tabernaemontana catharinensis (Apocynaceae). Molecules, 16, 7480-7487. https://doi.org/10.3390/molecules16097480

[15] Jiang, Z.G., Du, Q.Z. and Sheng, L.Y. (2009) Separation and Purification of Lentinan by Preparative High Speed Counter Current Chromatography. Chinese Journal of Analytical Chemistry, 37, 412-416.

[16] Shi, S., Zhang, Y., Huang, K., Liu, S. and Zhao, Y. (2008) Application of Preparative High-Speed Counter-Current Chromatography for Separation and Purification of Lignans from Taraxacum mongolicum. Food Chemistry, 108, 402-406. https://doi.org/10.1016/j.foodchem.2007.10.069

[17] Yin, L., Xu, Y., Qi, Y., Han, X., Xu, L., Peng, J. and Sun, C.K. (2010) A Green and Efficient Protocol for Industrial-Scale Preparation of Dioscin from Dioscorea nipponica Makino by Two-Step Macroporous Resin Column Chromatography. Chemical Engineering Journal, 165, 281-289. https://doi.org/10.1016/j.cej.2010.09.045

[18] Sun, P.C., Liu, Y., Yi, Y.T., Li, H.J., Fan, P. and Xia, C.H. (2015) Preliminary Enrichment and Separation of Chlorogenic Acid from Helianthus tuberosus L. Leaves Extract by Macroporous Resins. Food Chemistry, 168, 55-62. https://doi.org/10.1016/j.foodchem.2014.07.038

[19] Li, C.L., Shi, X.L., Men, Y., Yang, L. and Yang, A.M. (2014) Purification of Astragalus Polysaccharide with Macroporous Resins. Applied Mechanics and Materials, 618, 326-329. https://doi.org/10.4028/www.scientific.net/AMM.618.326

[20] Wang, C., Chao, Z., Wu, X., Sun, W. and Ito, Y. (2014) Enrichment and Purification of Pedunculoside and Syringin from the Barks of Ilex rotunda with Macroporous Resins. Journal of Liquid Chromatography \& Related Technologies, 37, 572-587. https://doi.org/10.1080/10826076.2012.749499

[21] Lv, X.H., Kuang, P.Q., Yuan, Q.P., Liang, H. and Zheng, G.Q. (2014) Preparative Separation of Steviol Glycosides from Stevia rebaudiana Bertoni by Macroporous Resin and Preparative HPLC. Acta Chromatographica, 26, 123-135. https://doi.org/10.1556/AChrom.26.2014.1.10

[22] Kim, E.J., Lee, H.J., Kim, H.J., Nam, H.S., Lee, M.K., Kim, H.Y. and Kim, H.Y. (2005) Comparison of Colorimetric Methods for the Determination of Flavonoid in Propolis Extract Products. Korean Journal of Food Science and Technology, 37, 918-921.

[23] Chang, C.C., Yang, M.H., Wen, H.M. and Chern, J.C. (2002) Estimation of Total Flavonoid Content in Propolis by Two Complementary Colorimetric Methods. Journal of Food and Drug Analysis, 10, 178-182.

[24] Afsar, M.Z., Hoque, S. and Osman, K.T. (2012) A Comparison of the Langmuir, 
Freundlich and Temkin Equations to Describe Phosphate Sorption Characteristics of Some Representative Soils of Bangladesh. International Journal of Soil Science, 7, 91-99. https://doi.org/10.3923/ijss.2012.91.99

[25] Tellan, A.C. and Owalude, S.O. (2007) Some Langmuir and Freundlich Parameters of Adsorption Studies of Chlorpheniramine Maleate. Research Journal of Applied Sciences, 2, 875-878.

[26] Xiao, F. and Pignatello, J.J. (2014) Effect of Adsorption Nonlinearity on the pH-Adsorption Profile of Ionizable Organic Compounds. Langmuir, 30, 1994-2001. https://doi.org/10.1021/la403859u

[27] Zhang, Y., Li, S.F., Wu, X.W. and Zhao, X. (2007) Macroporous Resin Adsorption for Purification of Flavonoids in Houttuynia cordata Thunb. Chinese Journal of Chemical Engineering, 15, 872-876. https://doi.org/10.1016/S1004-9541(08)60017-8

[28] Langmuir, I. (1918) Adsorption of Gases on Plain Surface of Glass, Mica and Platinum. Journal of the American Chemical Society, 40, 1361-1403. https://doi.org/10.1021/ja02242a004

[29] Freundlich, H. (1907) Kolloidfällung und Adsorption. Angewandte Chemie, 20, 749-750.

[30] Ferraro, V., Cruz, I.B., Jorge, R.F., Pintado, M.E. and Castro, P.M. (2013) Effects of Physical Parameters onto Adsorption of the Borderline Amino Acids Glycine, Lysine, Taurine, and Tryptophan upon Amberlite XAD16 Resin. Journal of Chemical \& Engineering Data, 58, 707-717. https://doi.org/10.1021/je301206r

[31] Zhao, Z.Y., Dong, L.L., Wu, Y.L. and Lin, F. (2011) Preliminary Separation and Purification of Rutin and Quercetin from Euonymus alatus (Thunb.) Siebold Extracts by Macroporous Resins. Food and Bioproducts Processing, 89, 266-272. https://doi.org/10.1016/j.fbp.2010.11.001

[32] Zhao, H., Wang, J., Jia, J., Liu, J., Ling, X.Q. and Lu, D.Q. (2010) Enrichment and Purification of Total Chlorogenic Acids from Tobacco Waste Extract with Macroporous Resins. Separation Science and Technology, 45, 794-800.

https://doi.org/10.1080/01496390903566713 